\title{
Determination of Diffused Irradiation from Horizontal Global Irradiation - Study for the City of Curitiba
}

\author{
Muriele Bester de Souza ${ }^{\star}$ \\ https://orcid.org/0000-0002-4510-5207 \\ Édwin Augusto Tonolo ${ }^{1}$ \\ https://orcid.org/0000-0002-8644-650X \\ Renata Lautert Yang ${ }^{1}$ \\ https://orcid.org/0000-0002-1867-229X \\ Gerson Máximo Tiepolo² \\ https://orcid.org/0000-0002-0409-4484 \\ Jair Urbanetz Junior ${ }^{2}$
https://orcid.org/0000-0001-9355-1730
}

1 Universidade Tecnológica Federal do Paraná - Postgraduate Program in Energy Systems (PPGSE), Solar Energy Laboratory (LABENS), - Paraná, Curitiba, Brazil; ${ }^{2}$ Universidade

Tecnológica Federal do Paraná - Academic Department of Electrical Engineering (DAELT), Solar Energy Laboratory (LABENS).

Received: 2018.11.05; Accepted: 2019.07.26.

* Correspondence: murielebester@gmail.com; Tel.: +55-41-996003310 (M. B. S.)

\section{HIGHLIGHTS}

- Review of solar radiation components.

- Acquisition of global irradiation data from INMET and UTFPR.

- Use of Liu and Jordan's and Page's method to calculate diffuse irradiation.

- Comparison with the results obtained in the Solar Energy Atlas - Paraná.

Abstract: Understanding the solar radiation values in the surface is important for the development of solar energy projects, obtaining through radiometers installed in certain places or publications as in solar energy atlases. Typically, solar or weather stations do not have sensors to measure diffuse irradiation due to high investment and the need for constant maintenance. This paper presents methods for the determination of diffuse irradiation from surface measured data of global horizontal irradiation in the city of Curitiba, obtained through pyranometers installed at the Federal University of Technology - Paraná (UTFPR) headquarters and from Curitiba-A807 National Institute of Meteorology (INMET) station. Two models are presented for the estimation of the monthly mean daily diffuse irradiation, based on the studies of Liu and Jordan (1960) and Page (1961). Finally, these data were compared with those presented by the Solar Energy Atlas - Paraná, verifying the percentage differences presented. It was observed that the model elaborated by Page presented better results in the diffuse radiation estimates when compared to the values 
presented by the Paraná Atlas, with an average variation of $-1.39 \%$ and $-1.55 \%$, for data from INMET and UTFPR respectively.

Keywords: Diffuse Irradiation, estimate, global irradiation, solar energy.

\section{INTRODUCTION}

Solar energy is not a renewable source of energy but an inexhaustible source of energy [1]. The publication by INPE (National Institute for Space Research) of the Brazilian Solar Energy Atlas 2nd edition (2017) shows that Brazil has great solar potential, where even in the less sunny place it is viable to install photovoltaic solar energy systems.

In December 2017, the first Solar Energy Atlas - Paraná was published, whose project was the result of a partnership between UTFPR, INPE, Itaipu Binational and the Itaipu Technological Park (PTI). However, during the project, it was perceived a difficulty in validating the data estimated by the BRASIL-SR model with the surface's collected data, since the state of Paraná does not have its own solarimetric grid, needing this information to improve it and develop new research in this sector, whether thermosolar or photovoltaic systems.

Each system has its way of operation: thermals depend exclusively on direct solar irradiance, whereas photovoltaics uses all available irradiance, either on a fixed inclined plane or through solar trackers [2]. In Figure 1 is presented a basic representation of the solar radiation components, according to the Solar Energy Atlas - Paraná [3].

According to Pinho and Galdino [4] the radiation components are described as:

Extraterrestrial irradiance: Solar irradiance that reaches the top of the Earth's atmospheric layer.

Beam irradiation: Solar irradiation that focus directly on the surface without any influence.

Diffuse irradiation: Solar irradiation that reaches the surface after being scattered throughout the earth's atmosphere.

Reflected irradiation (albedo): irradiation reflected by the surrounding environment (soil, vegetation, obstacles, rocky terrain, etc.).

Global irradiation: amount of irradiation resulting from the sum of direct, diffuse and albedo solar irradiations. 


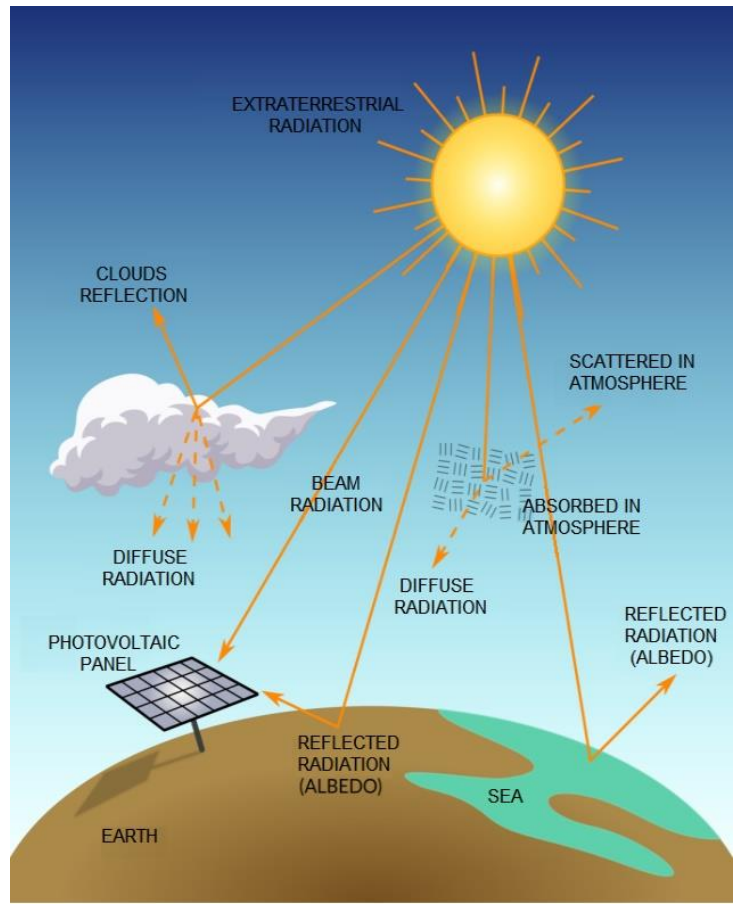

Figure 1. Representation of Solar Radiation Components.

For photovoltaic use, the most interesting is the global horizontal irradiation, which quantifies the radiation received by a horizontal flat surface. On cloudy days, the main portion is from the horizontal diffuse irradiation, whereas on clear days direct irradiation prevails [5].

Currently at INMET's climatological stations, only the horizontal global component is collected. The accuracy and quality of solar radiation data collected by equipment is very important and depends on the manufacturer's recommended installation, operation, and maintenance, and should follow the International Organization for Standardization (ISO) and World Meteorological Organization (WMO) that establish ratings and specifications for solar irradiance measurement [1].

Due to the different characteristics of the components and the difficulty of obtaining the diffuse fraction out of the measured data, this work aims to determine the diffuse irradiation from global horizontal surface measured irradiation in the city of Curitiba, using the models studied by Liu and Jordan [6] and Page [7], and compare the data estimated by these models with the data presented in the Solar Energy Atlas - Paraná.

\section{MATERIAL AND METHODS}

Global radiation is monitored by two KIPP \& ZONEN - CMP3 Second Class thermoelectric pyranometers [8], as shown in Figure 2 and positioned in a horizontal plane. The data obtained are from 12 months, from June 2017 to May 2018 and were acquired from INMET's pyranometer installed at Curitiba-A807 Station [9], Curitiba - PR, with latitude of $25^{\circ} 26.922^{\prime} S$ and longitude of $49^{\circ} 13.836^{\prime} \mathrm{W}$. The other pyranometer is located at UTFPR, Curitiba central campus, located at 3165 Sete de Setembro Avenue, with latitude 2526.352' S and longitude 49⒗176' W. 


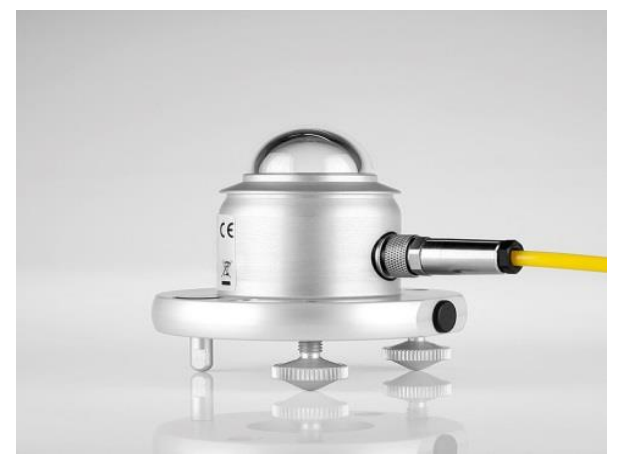

Figure 2. Pyranometer CMP3.

The data collected from the horizontal global component, both by the weather station and by the UTFPR, are in solar irradiance $\left(\mathrm{W} / \mathrm{m}^{2}\right)$, stored hourly, therefore, they are also hourly solar irradiation data $\left(\mathrm{Wh} / \mathrm{m}^{2}\right)$. To estimate diffuse irradiation, assumptions and calculations presented in this section are required.

Extraterrestrial solar radiation on a horizontal surface is obtained, according to Macagnan [10], by Equation 1:

$$
\text { Ion }=\text { Isc. Eo }
$$

where, Ion is the extraterrestrial irradiance, Isc is the solar constant equal to $1367 \mathrm{~W} / \mathrm{m}^{2}$ and Eo is the earth-orbit eccentricity correction factor, described in Equation 2:

$$
\text { Eo }=\operatorname{Isc}\left(1+0,033 \cdot \cos \frac{360 . n}{365}\right)
$$

Where $\mathrm{n}$ is the day in the Julian calendar, ranging from 1 (January 1 ) to 365 (December 31), shown in Table 1.

Table 1. Standard average day of the month.

\begin{tabular}{ccccc}
\hline \multirow{2}{*}{ Month } & $\begin{array}{c}\text { n for i:th } \\
\text { Day of the month }\end{array}$ & \multicolumn{3}{c}{ For the average day of the month } \\
\cline { 3 - 5 } & & Date & $\begin{array}{c}\mathbf{n}, \\
\text { day of the year }\end{array}$ & $\begin{array}{c}\mathbf{\delta}, \\
\text { declination }\left(^{\circ}\right)\end{array}$ \\
\hline January & $\mathrm{i}$ & 17 & 17 & -20.9 \\
February & $31+\mathrm{i}$ & 16 & 47 & -13 \\
March & $59+\mathrm{i}$ & 16 & 75 & -2.4 \\
April & $90+\mathrm{i}$ & 15 & 105 & 9.4 \\
May & $120+\mathrm{i}$ & 15 & 135 & 18.8 \\
June & $151+\mathrm{i}$ & 11 & 162 & 23.1 \\
July & $181+\mathrm{i}$ & 17 & 198 & 21.2 \\
August & $212+\mathrm{i}$ & 16 & 228 & 13.5 \\
September & $243+\mathrm{i}$ & 15 & 258 & 2.2 \\
October & $273+\mathrm{i}$ & 15 & 288 & -9.6 \\
November & $304+\mathrm{i}$ & 14 & 318 & -18.9 \\
December & $334+\mathrm{i}$ & 10 & 344 & -23 \\
\hline & & Data obtained in [10].
\end{tabular}

By obtaining the solar irradiation data on the terrestrial surface through the INMET and UTFPR pyranometers, and from the extraterrestrial irradiation calculation, it is obtained the values of the atmospheric transmissivity index $(\mathrm{Kt})$, which is defined as the ratio between the solar radiation on the earth's surface $(H)$ to the solar radiation reaching the top of the 
atmosphere (Ho). It varies according to the amount of clouds and aerosols in the atmosphere, and there may be increase or decrease of direct or diffuse components of solar radiation that reach the surface [11]. Kt is defined by Equation 3:

$$
\mathrm{Kt}=\frac{\mathrm{H}}{\mathrm{Ho}}
$$

To calculate monthly mean daily horizontal extraterrestrial irradiation, the average day of the year is used, which is the day of the year when daily extraterrestrial radiation is almost equal to the monthly average value. It was noted that the 16th day of each month can lead to minor errors in Ho, especially for June and December, which are the solstices. The recommended days for each month are given in Table 1. It can be estimated Ho from Equation 4:

$$
\text { Ho }=\frac{24}{\pi} \cdot \operatorname{Isc} \cdot \operatorname{Eo}\left[\left(\frac{\pi}{180}\right) \cdot \omega \mathrm{s} \cdot(\sin (\delta) \cdot \sin (\varphi))+(\cos (\delta) \cdot \cos (\varphi) \cdot \sin (\omega \mathrm{s}))\right]
$$

where, $\omega s$ is the angle of the sun's rise, in degrees, and can be obtained from Equation 5:

$$
\omega \mathrm{s}=\cos ^{-1}(-\operatorname{tg}(\varphi) \cdot \operatorname{tg}(\delta))
$$

where $\varphi$ is the local latitude, in degrees and $\delta$ is the solar declination, in degrees, and is calculated from Equation 6

$$
\delta=23,45^{\circ} \cdot \sin \left(360 \frac{284+\mathrm{n}}{365}\right)
$$

After determining the $\mathrm{Kt}$ index, it is estimated the variation of the daily diffuse fraction $\mathrm{Kd}$, which is the ratio between diffuse irradiation $\mathrm{Hd}$ and global horizontal irradiation in the surface $\mathrm{H}$, and is defined by the Equation 7 :

$$
\mathrm{Kd}=\frac{\mathrm{Hd}}{\mathrm{H}}
$$

The first method used to estimate the monthly mean daily diffuse solar irradiation on horizontal surface was Liu and Jordan's [6], is defined by Equation 8 and has as its parameter the Kt index.

$$
\frac{\mathrm{Hd}}{\mathrm{H}}=1,39-4,027 \cdot \mathrm{Kt}+5,531 \cdot \mathrm{Kt}^{2}-3,108 \cdot \mathrm{Kt}^{3}
$$

The second method used to estimate the monthly mean daily diffuse solar irradiation was Page's [7] and is defined by Equation 9, also as a function of the Kt index:

$$
\frac{\mathrm{Hd}}{\mathrm{H}}=1,00-1,13 . \mathrm{Kt}
$$

\section{RESULTS}

Through the data obtained by the INMET and UTFPR's pyranometers, in the 12-month period (June 2017 to May 2018), it can be seen that these values, compared to the Solar Energy Atlas - Paraná, presented values close to the Atlas, which has estimates of solar radiation based on 17 years of satellite data (1999 to 2015).

Table 2 and Table 3 show the months of the year analyzed, the calculated values of transmissivity indices $(\mathrm{Kt})$ and diffuse fraction $(\mathrm{Kd})$ for INMET and UTFPR.

Measured horizontal global irradiation and estimated horizontal diffuse irradiation according to the Liu - Jordan and Page methods, respectively, were also presented. Finally, the percentage variation between the diffuse irradiation values estimated by the models and those presented by the Solar Energy Atlas - Paraná is presented.

The indices $\mathrm{Kt}$ and $\mathrm{Kd}$ are dimensionless values, since they represent the fraction of the components that arrive at surface, being the global and diffuse irradiations represented in $\mathrm{W} . \mathrm{h} / \mathrm{m}^{2}$.day.

The methods for determination of the diffuse irradiation component chosen from Liu and Jordan (Table 2) and Page (Table 3) presented expected diffuse irradiation data when 
compared to those presented by the Atlas, where it is assumed that the models are viable to estimate it.

Table 2. Comparison of data with calculated Kd by the Liu and Jordan's method.

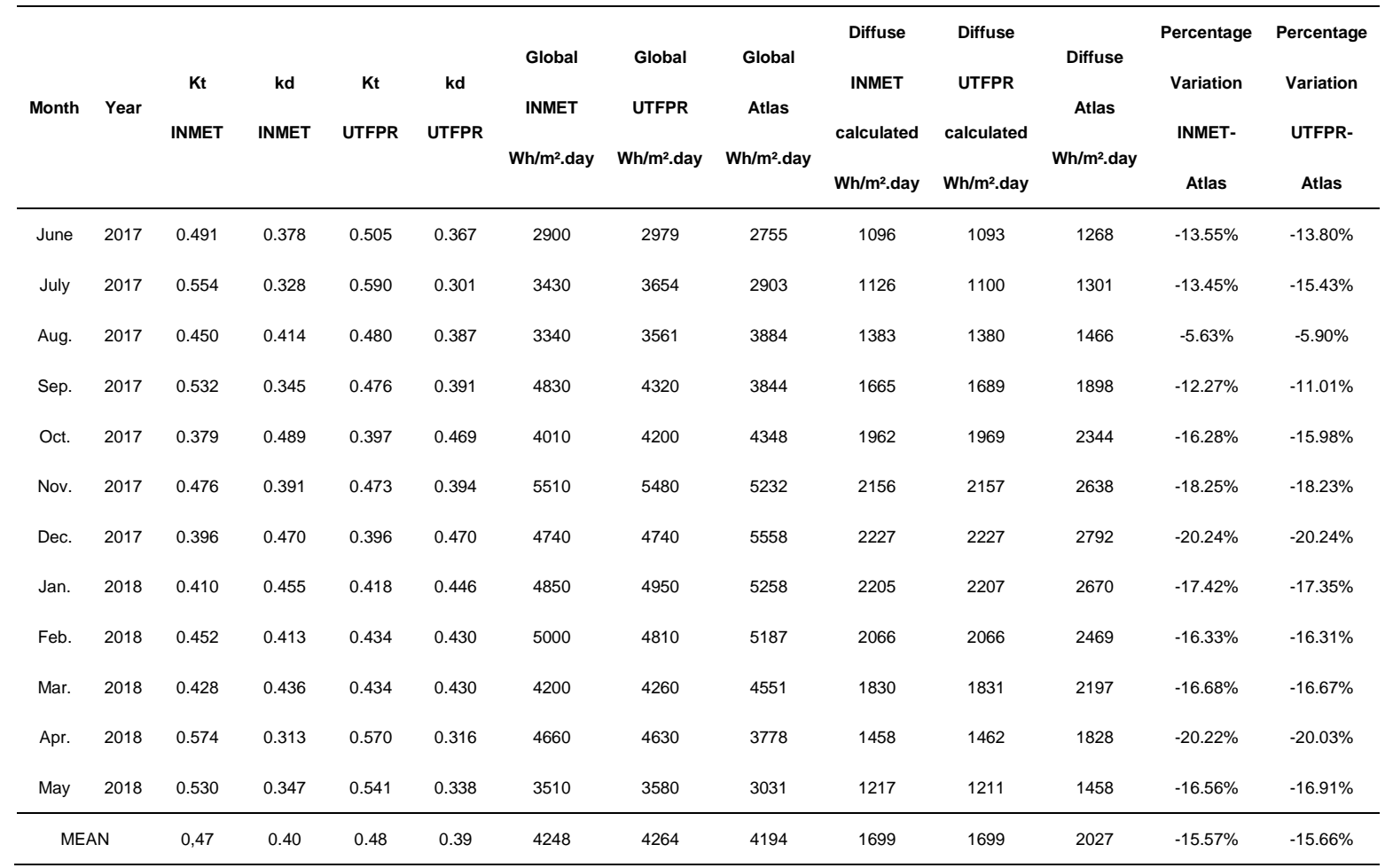

Comparison between the Solar Energy Atlas - Paraná with those obtained by INMET station and UTFPR.

Table 3. Comparison of data with calculated Kd by the Page's method.

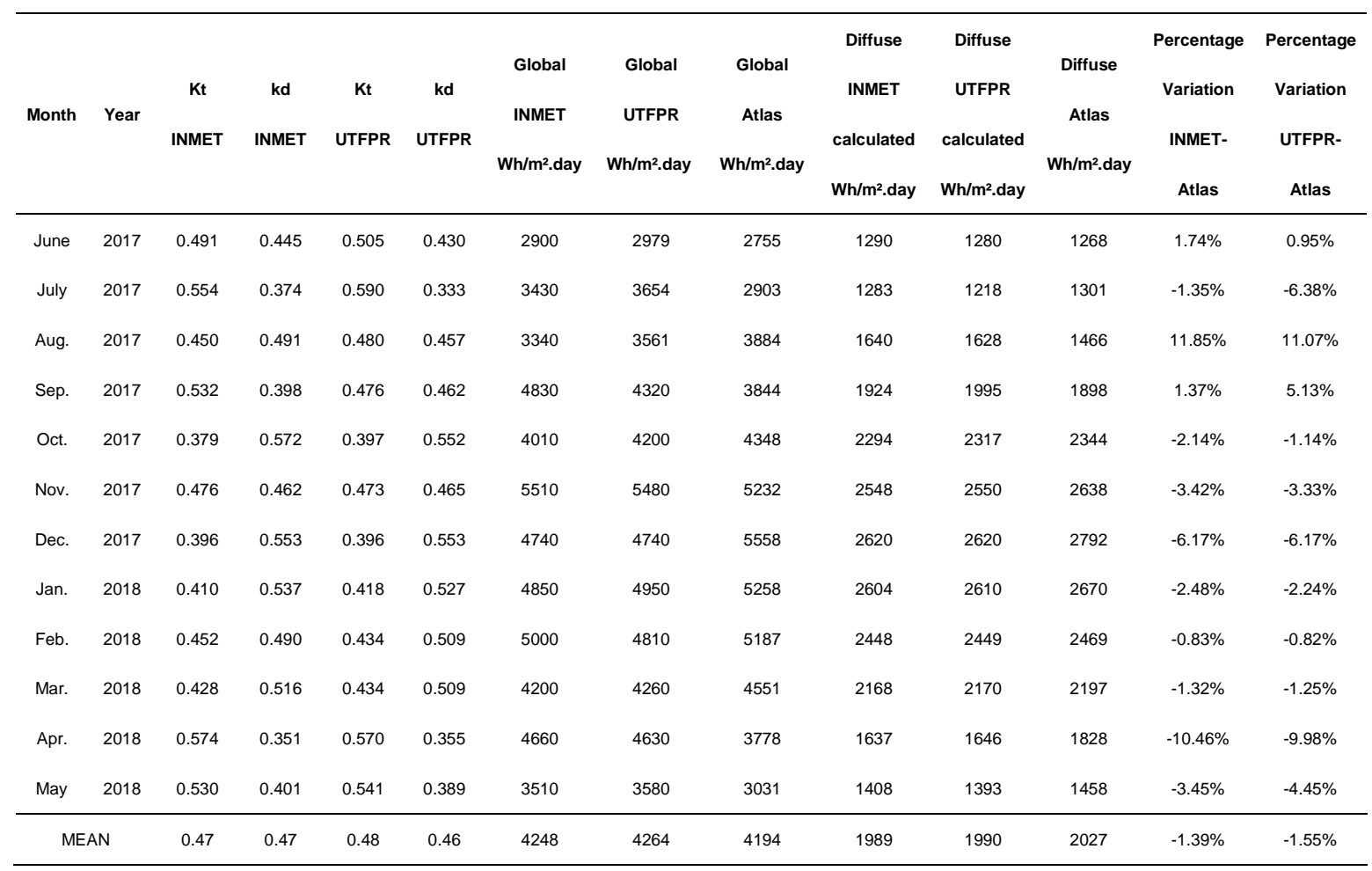

Comparison between the Solar Energy Atlas - Paraná with those obtained by INMET station and UTFPR. 


\section{DISCUSSION}

It was found that the mean variation between diffuse irradiation obtained by the Liu and Jordan method for UTFPR in relation to Atlas is $-16 \%$, the same percentage found among the values obtained for INMET in relation to Atlas. This shows that the data obtained by the studied sites are very similar and have a considerable average variation in relation to the Atlas data, which was the reference used.

However, for the Page method, the average variation of diffuse irradiation presented between the values obtained for UTFPR in relation to Atlas was $-1.55 \%$, while for INMET the variation was $-1.39 \%$. These results show that the studied methods presented values very close to those found in the Atlas in the analyzed period.

Studies such as Crotti and Rampinelli [13] show that the lower the value of the Kt index, the higher the value of the Kd index, which can be observed in Figure 3 and Figure 4. This shows the convergence of the studies to different locations analyzed, proving the validation of the used methods.

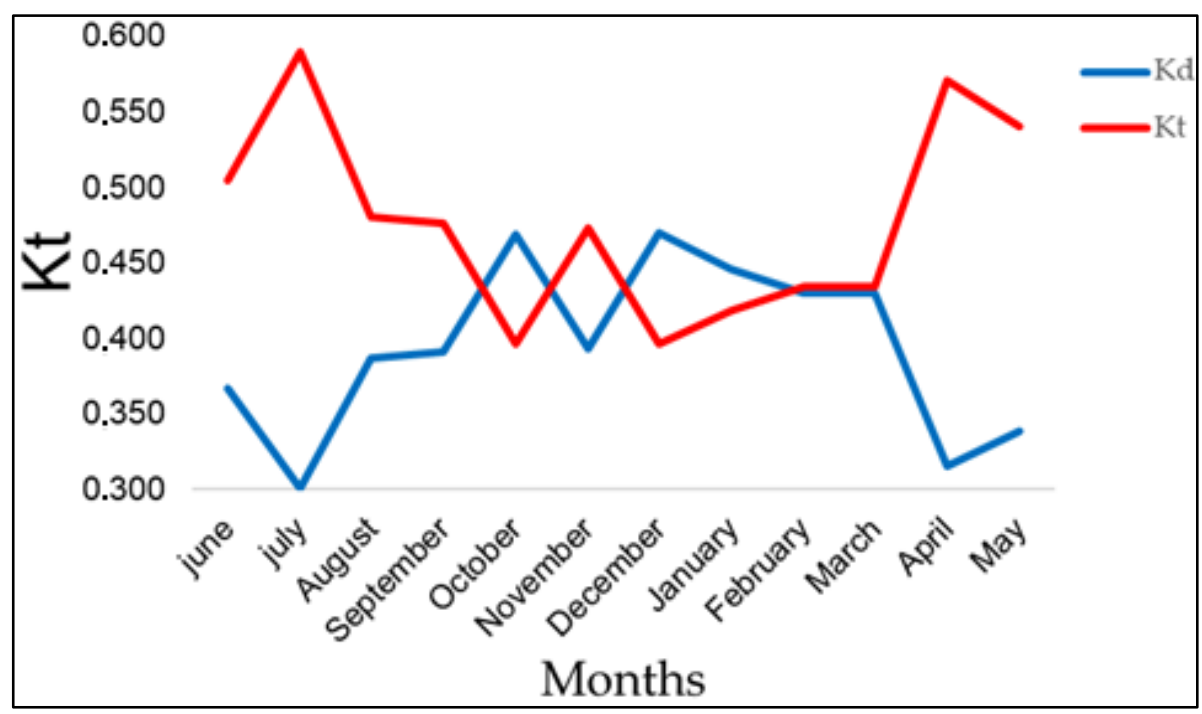

Figure 3. Comparison between Kt and Kd (Liu e Jordan's method). 


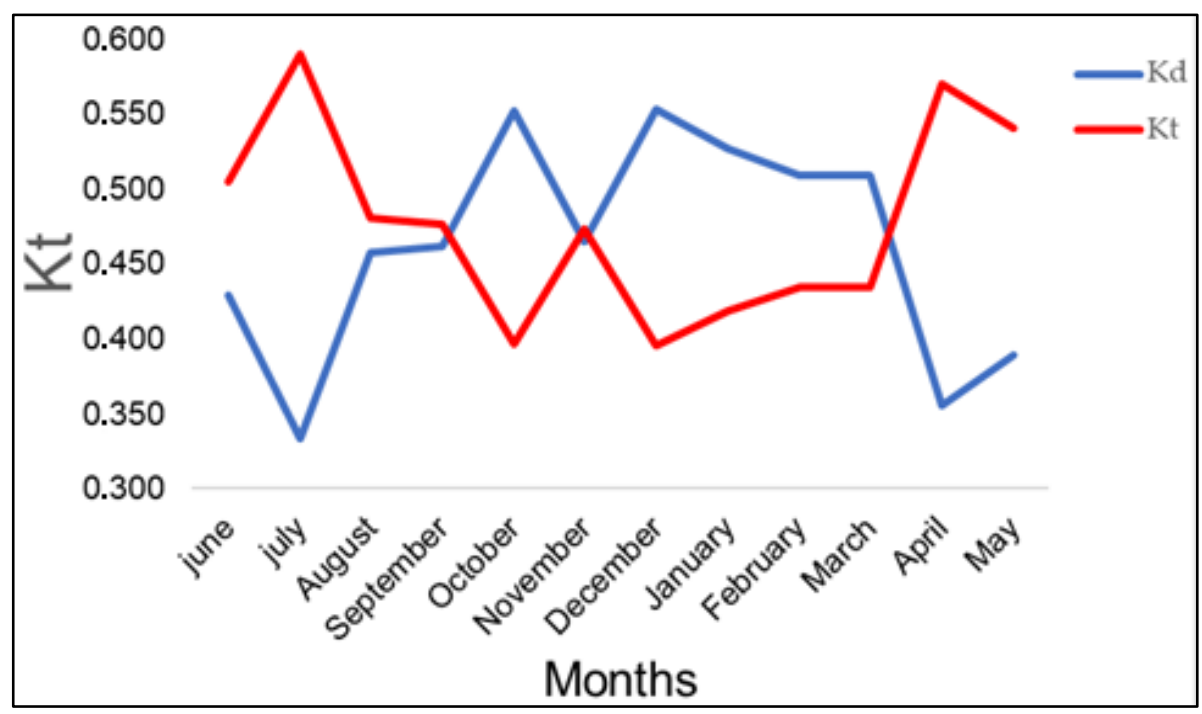

Figure 4. Comparison between Kt and Kd (Page's method).

\section{CONCLUSION}

This work presented analyzes for models in order to estimate the average daily diffuse irradiation by choosing Liu and Jordan's and Page's models. With the results presented in Tables 2 and 3, there was less variation between the data when calculated by the Page's method. This does not mean that the Liu and Jordan's method is less reliable, because it must be taken into account that the studied period is short compared to the values presented in the Solar Energy Atlas - Paraná in which a comprehensive historical data, between 1999 and 2015, was used.

It can also be seen from the comparisons that the data measured by the INMETCuritiba Station and the UTFPR, of horizontal global irradiation are similar.

It was found that in the periods between April and August (autumn and winter seasons) the proportion of diffuse irradiation was smaller than in the other months of the year, characterized by less cloudiness and sunnier days compared to other periods of the year. This information is confirmed by the maps presented in the Solar Energy Atlas - Paraná, where seasonal daily averages of diffuse irradiation are shown.

Finally, to know which of these models presents the best estimate of diffuse irradiation, it would be ideal to obtain the measured values of this component, which is intended to be accomplished in a next step of this research.

Acknowledgments: The authors would like to thank UTFPR for the support and infrastructure available for the development of this research, and COPEL - Distribution for the support and funding of the resources for the realization of this R\&D project "ANEEL RD 2866-0464 / 2017 METHODOLOGY FOR ANALYSIS, MONITORING AND MANAGEMENT BY ENCOURAGED SOURCES".

\section{REFERENCES}

1. Pereira, E.; Martins, F.; Gonçalves, A.; Costa, R.; Lima F.; Rüther, R.; Abreu, S.; Tiepolo, G.; Pereira, S.; Souza, J. Brazilian Atlas of Solar Energy, 2nd ed.; National Space Research Institute: São José dos Campos, Brazil, 2017; pp. 09-68.

2. Souza, G. K.; Macagnan M. H. Comparison of hourly diffuse radiation models from data measured by SONDA station network in some cities in Brazil. VII CBENS 2018, 01-09.

3. Tiepolo, G; Pereira, E.; Urbanetz JR, J.; Pereira, S.; Gonçalves, A.; Lima, F.; Costa, R.; Alves, A. Solar Energy Atlas - Paraná, 1st ed.; National Space Research Institute: São José dos Campos, Brazil, 2017; pp. 10-84. 
4. Pinho, J.; Galdino, M. Engineering Manual for Photovoltaic Systems. Rio de Janeiro: Cresesb Cepel; 2014. p. 66-101.

5. Energy Research Company. Technical Note: Analysis of Solar Generation Insertion in the Brazilian Electrical Matrix. Available online: http://www.cogen.com.br/content/upload/1/documentos/Solar/Solar_COGEN/NT_EnergiaSolar 2012.pdf (accessed on 14 July 2018).

6. Liu, B.Y.H.; Jordan, R.C. The interrelationship and characteristic distribution of direct, diffuse and total solar radiation. Solar Energy 1960, v.4, pp.01-19.

7. Page, J. K. The estimation of monthly mean values of daily total short-wave radiation on vertical and inclined surfaces from sunshine records for latitudes $40^{\circ} \mathrm{N}-40^{\circ} \mathrm{S}$. Proc. U.N. Conf. New Sources Energy 1961, Vol 4, pp. 378-390.

8. KIPP\&ZONEN. Kipp \& Zonen. Available online: http://www.kippzonen.com/ (accessed on 14 July 2018).

9. National Institute of Meteorology. Available online: http://www.inmet.gov.br (accessed on 16 July 2018).

10. Macgnan, H.M. Introduction to solar radiation. Sinos River Valley University: São Leopoldo, Brazil, 2010; pp. 02-90.

11. Querino, C. A.; Moura, M. A.; Silva Querino, J. K.; Filho, A. O. Study of Global Solar Radiation and External and Internal Transmissivity Index (Kt) in a mangrove forest in Alagoas - Brazil. RBMET 2011, v.26, pp.204-294.

12. Klein, S. A. Calculation of montlhly average insolation on tilted surfaces. Solar Energy 1977, Vol 19, pp. 325-329.

13. Crotti, P.; Rampinelli, G. A. Estimation of the direct and diffuse solar components in horizontal surface for Araranguá/SC from meteorological networks. VII CBENS 2018, 01-09. 